\title{
Thinking-aloud protocols. A method for analysing how readers comprehend and experience texts
}

\section{ANNE KJÆRGAARD, GITTE GRAVENGAARD, SINE HJU- LER AND CAMILLA DINDLER}

How do readers react to communication products written by public service institutions and private organisations? How - and how well - do readers comprehend this type of communication products, and how do they perceive them? In this article we argue that thinking-aloud protocols can contribute to answering these questions, and that the results of the analysis of such protocols can have a positive impact on the development of communication products. Thinking-aloud protocols are collected by asking a person to read a text aloud and tell what he or she thinks while reading it. The method originates from psychological studies of cognitive processes. However, we adopt a social constructivist framework and thereby assume that the protocols illuminate how knowledge, relations, identities, and comprehension are constructed through interaction between researchers, informants and communication products. Based on our own thinking-aloud protocols, the article demonstrates how to collect protocols within a social constructivist framework. Furthermore, the article illustrates how linguistic analytical strategies - critical discourse analysis, cognitive metaphor theory and narrative theory - can inform the analysis of thinking-aloud protocols. These theories make it possible to illuminate the construction of knowledge, relations, and comprehensions in the protocols. Finally, we argue that the thinking-aloud method can be applied as an interventionist method for the purpose of strengthening the strategic communication of organisations and make it easier for citizens to comprehend their rights and duties. 